\title{
Two-Dimensional Modeling of Silicon Nanowires Radial Core-Shell Solar Cells
}

\author{
Qiang Zeng, 1 Na Meng, ${ }^{1}$ Yulong Ma, ${ }^{1}$ Han Gu, ${ }^{1}$ Jing Zhang, ${ }^{1}$ Qingzhu Wei, \\ Yawei Kuang $\mathbb{D}^{1}{ }^{1}$ Xifeng Yang, ${ }^{1}$ and Yushen Liu ${ }^{1}$ \\ ${ }^{1}$ School of Physics and Electronic Engineering, Changshu Institute of Technology, Changshu 215500, China \\ ${ }^{2}$ Suzhou Talesun Solar Technologies Co., Ltd., Changshu 215500, China \\ Correspondence should be addressed to Yawei Kuang; david01124@163.com
}

Received 7 February 2018; Revised 13 April 2018; Accepted 22 April 2018; Published 24 May 2018

Academic Editor: Markus R. Wagner

Copyright (C) 2018 Qiang Zeng et al. This is an open access article distributed under the Creative Commons Attribution License, which permits unrestricted use, distribution, and reproduction in any medium, provided the original work is properly cited.

\begin{abstract}
Silicon nanowires radial core-shell solar cells have recently attracted significant attention as promising candidates for low cost photovoltaic application, benefit from its strong light trapping, and short radial carrier collection distances. In order to establish optics and electricity improvement, a two-dimensional model based on Shockley-Read-Hall recombination modes has been carried out for radial core-shell junction nanowires solar cell combined with guided resonance modes of light absorption. The impact of SiNWs diameter and absorption layer thickness on device electrical performance based on a fixed nanowires height and diameterover-periodicity were investigated under illumination. The variation in quantum efficiency indicated that the performance is limited by the mismatch between light absorption and carriers' collection length.
\end{abstract}

\section{Introduction}

Silicon is a widely used material for solar energy conversion because of its excellent electrical properties, superior mechanical and thermal properties, and mature processing techniques. However, silicon is not considered as an ideal photovoltaic material because of its indirect band gap and low absorption efficiency in the visible-infrared region. Therefore, a thick and high quality silicon substrate which has a long minority carriers' diffusion length is essential for light absorption. The tradeoff between the light absorption and minority carriers collection is a key issue for high performance device $[1,2]$.

Recent developments are the shift from bulk silicon based solar cell to nanowires core-shell junction solar cell with radial structure [3]. Due to limited dimension and large surface-to-volume ratio, nanowires devices are more likely to exhibit unique properties especially for high performance photoelectric devices [4,5]. The performance is mostly affected by several issues such as lattice quality and electrode contact $[6,7]$. Among that, silicon nanowires (SiNWs) core-shell solar cells with a $p$ - $n$ junction were reported as promising solutions for energy efficient conversion. The excited carriers for planar substrate need longer distance to be extracted compared with radial SiNWs solar cell which has the advantage to enhance the cell efficiency due to the orthogonal direction between carrier collection and light absorption [8]. It was pointed that wire dimensions such as height, radius, cycle, and junction formed parameters such as surface recombination rate, junction technical process, and doping concentration all have effects on light absorption and electrical characteristics [9].

Nanowires based solar cell in the field of fabrication technique and materials properties were studied a lot; however, numerical simulations were rarely reported [10, 11]. Based on efficient light trapping design, the ration of nanowire diameter and periodicity should exceed 0.5 for the optimized solar spectral absorption [12-14]. Previous modeling mainly focused on light absorption enhancement for optimum periodic SiNWs arrays, yet the relationships between fabrication and performance aspects are difficult to predict and design $[15,16]$.

In order to apply a periodic array structure for practical radial junction solar cell, fabrication process should be taken into light trapping and carriers' collection since it is responsible for conversion efficiency. Thus, $2 \mathrm{D}$ simulations 

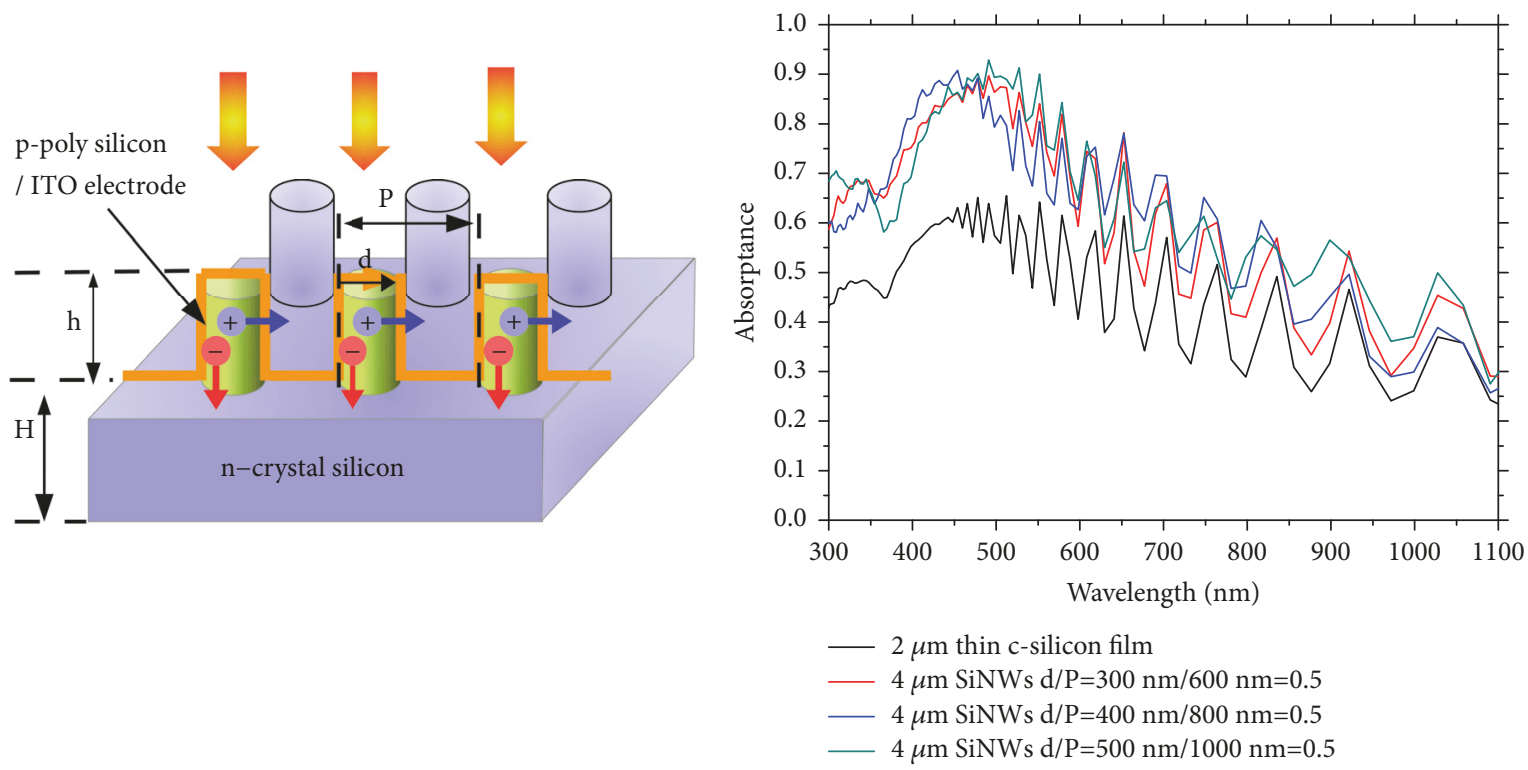

(a)

(b)

Figure 1: (a) Schematic of nanowires radial core-shell junction solar cell used in the model. The incident light is in parallel to the SiNWs axis; (b) optical absorption spectra of the SiNWs array versus diameter $300 \mathrm{~nm}, 400 \mathrm{~nm}$, and $500 \mathrm{~nm} .2 \mu \mathrm{m}$ thick silicon substrate serves as reference. The radio of $d / P$ is set as 0.5 .

are necessary for such contribution. In this work, we mainly investigated the impact of SiNWs diameter $(d)$ on device electrical performance based on a fixed nanowires height $(h)$ and diameter-over-periodicity $(d / P)$. To accomplish this task, light absorption spectrum was calculated by Finite Difference Time Domain (FDTD) method and silicon nanowires fabrication via direct etching technical was calculated using physics-based 2D Technology Computer Aided Design (TCAD) tools.

\section{Materials and Methods}

2.1. Optical Absorption. A periodic array structure was designed as shown in Figure 1(a); the device shows $4 \mu \mathrm{m}$ height nanowires with diameter selected as $0.3 \mu \mathrm{m}, 0.4 \mu \mathrm{m}$, and $0.5 \mu \mathrm{m}$ on the $2 \mu \mathrm{m}$ n-type crystal silicon substrate, the ratio of diameter-over-periodicity $(d / P)$ based on a fixed value as 0.5. The radial core-shell junction is consisting of an n-type silicon nanowire core surrounded by a p-doped shell. A layer of Indium-doped Tin Oxide (ITO) with an optimal thickness was formed as cathode to collect photo generated carriers.

Lumerical FDTD Solutions software was used for simulations in light trapping; the light source was considered a plane wave source range from $300 \mathrm{~nm}$ to $1100 \mathrm{~nm}$ parallel to the SiNWs axis. Figure 1(b) depicts the absorption spectra of the SiNWs array with different $\mathrm{d}$ and the fixed $d / P$ ratio of 0.5 . The increase in the diameter would also shift the absorption edge. The case of $d$ at $400 \mathrm{~nm}$ is that the absorption edge shifts toward high energy region while the absorption edge shifts toward low energy region of diameter at $500 \mathrm{~nm}$. It means that $300 \mathrm{~nm}$ diameter has the maximal absorption area. The light absorption is dramatically improved by all the SiNWs arrays compared with the $2 \mu \mathrm{m}$ thick planar silicon substrate.

2.2. Structure Fabrication. The SiNWs core-shell junction solar cells were structured using direct dry etching method simulated by Silvaco Athena. At a first step, $6 \mu \mathrm{m}$ thick crystal substrate is $\langle 100\rangle$ silicon region of $1.0 \mu \mathrm{m} \times 8.0 \mu \mathrm{m}$ size, which is uniformly doped with phos.c of $1 \times 10^{13} \mathrm{~cm}^{-3}$. The dry etching step etches the specified material in the region between the exposed top boundary and a line obtained by translating the boundary line down in the Y direction of 4 $\mu \mathrm{m}$. After n-type nanowires core was finished, $1.0 \mu \mathrm{m} \times 4.0 \mu \mathrm{m}$ oxide window was formed to decrease surface recombination. As a final step, $50 \mathrm{~nm}$ poly silicon layer doped with boron.c of $1 \times 10^{16} \mathrm{~cm}^{-3}$ and $100 \mathrm{~nm}$ ITO film was deposited, respectively.

The generated band diagram was shown in Figure 2(b); we constructed a 2D cylindrical radial cell model developing from planar geometry device [17]. The emitter layer was set as n-type crystal silicon while the base layer was assumed as p-type poly silicon. Vertical incident light was set on the top of the array centre and the absorption spectra have got from FDTD results. The surface recombination was described as the following equation based on the Shockley-Read-Hall $(\mathrm{SRH})$ recombination model:

$$
R_{S R H}=\frac{p n-n_{i e}^{2}}{\tau_{p}\left[n+n_{i e} \exp \left(\left(E_{t}-E_{f}\right) / k_{B} T\right)\right]+\tau_{n}\left[p+n_{i e} \exp \left(\left(E_{f}-E_{t}\right) / k_{B} T\right)\right]},
$$




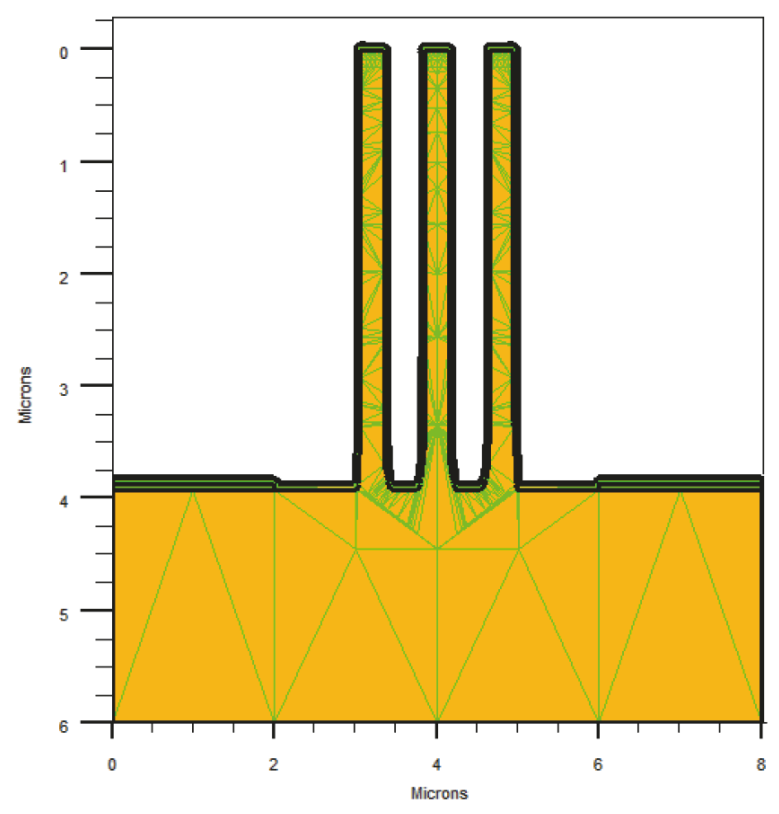

(a)

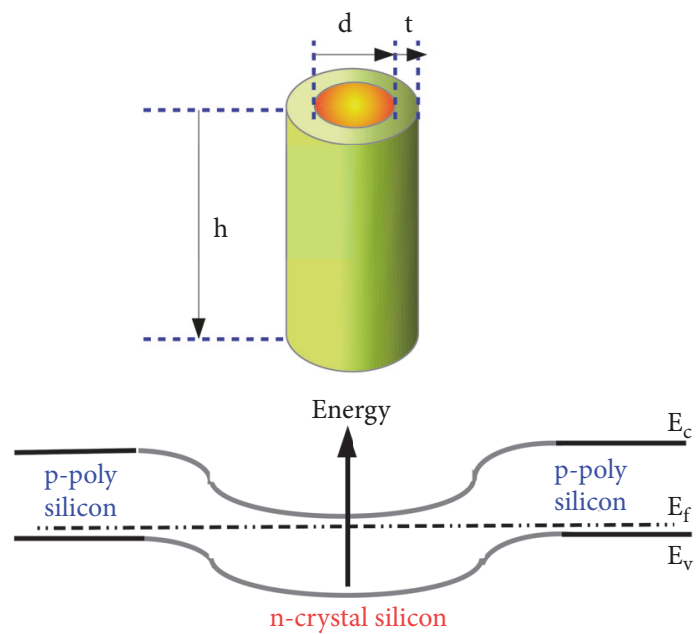

(b)

FIGURE 2: (a) Cross section of the radial junction nanowire cell; (b) energy band diagram of a single nanowire core-shell junction solar cell.

where $\tau_{n}$ and $\tau_{p}$ are the electrons and holes lifetime that depend on the silicon doping concentration and $n_{i e}$ is the effective intrinsic carrier concentration. $E_{f}$ is the intrinsic Fermi level of silicon. $T$ is the lattice temperature in degrees Kelvin. $n$ and $p$ are the electron and hole concentrations, respectively.

The material parameters for crystal and poly silicon have been obtained from experimentally available data as listed in Table 1; more detail about Silvaco simulation could be found in $[18-20]$.

\section{Results and Discussion}

3.1. Compared with Planar Device. To understand the relationship between optical and potential performance of the core-shell structure, we have simulated the photogeneration rate at $\mathrm{Y}$ direction of the planar and radial junction, respectively. As shown in Figure 3, nanowire array structure not only increased light absorption length, but also concentrated the light field which results from an increased excitation of photo induced carriers.

Figure 4(a) gives the linear light and dark $J-V$ curves of the planar and core-shell cells based a fixed substrate thick of 2 $\mu \mathrm{m}$. Under AM.1.5 illumination, the $V_{o c}$ and $J_{s c}$ values of 0.145 $\mathrm{V}$ and $9.52 \mathrm{~mA} / \mathrm{cm}^{2}$ for radial solar cell are both higher than $0.112 \mathrm{~V}$ and $3.36 \mathrm{~mA} / \mathrm{cm}^{2}$ for planar solar cell. This suggests that the nanowire array provides a strong light trapping effect. We noticed that the trend of $J_{s c}$ is also consistent with the value obtained from the External Quantum Efficiency (EQE) response of the radial junction solar cell presented in Figure 4(b).

On the other hand, the Internal Quantum Efficiency (IQE) response shows that radial junction solar cell has lower
TABLE 1: List of modeling parameters and defect distributions.

\begin{tabular}{|c|c|c|}
\hline Parameter & Description & Values \\
\hline $\mathrm{E}_{\mathrm{g} 1}$ & $\begin{array}{l}\text { Crystal silicon } \\
\text { energy band }\end{array}$ & $1.12 \mathrm{ev}$ \\
\hline $\mathrm{E}_{\mathrm{g} 2}$ & $\begin{array}{c}\text { Poly silicon energy } \\
\text { band }\end{array}$ & $1.12 \mathrm{ev}$ \\
\hline d & $\begin{array}{c}\text { Si nanowires } \\
\text { diameter }\end{array}$ & $300 / 400 / 500 \mathrm{~nm}$ \\
\hline $\mathrm{P}$ & $\begin{array}{c}\text { Si nanowires array } \\
\text { periodicity }\end{array}$ & $600 / 800 / 1000 \mathrm{~nm}$ \\
\hline $\mathrm{h}$ & $\begin{array}{l}\text { Si nanowires } \\
\text { length }\end{array}$ & $4 \mu \mathrm{m}$ \\
\hline $\mathrm{H}$ & $\begin{array}{l}\text { Thickness of n-type } \\
\text { silicon substrate }\end{array}$ & $2 \mu \mathrm{m}$ \\
\hline phos.c & $\begin{array}{c}\text { n-type } \\
\text { concentration of Si }\end{array}$ & $1 \times 10^{13} \mathrm{~cm}^{-3}$ \\
\hline $\mathrm{N}_{\mathrm{c}}$ & $\begin{array}{l}\text { Effective density of } \\
\text { states in silicon CB }\end{array}$ & $2.8 \times 10^{19} \mathrm{~cm}^{-3}$ \\
\hline $\mathrm{t}$ & $\begin{array}{l}\text { Thickness of p-type } \\
\text { poly silicon shell }\end{array}$ & $0.05 \mu \mathrm{m}$ \\
\hline $\mathrm{N}_{\mathrm{v}}$ & $\begin{array}{l}\text { Effective density of } \\
\text { states in silicon VB }\end{array}$ & $1.04 \times 10^{19} \mathrm{~cm}^{-3}$ \\
\hline boron.c & $\begin{array}{c}\text { p-type } \\
\text { concentration of } \\
\text { poly Si }\end{array}$ & $1 \times 10^{16} \mathrm{~cm}^{-3}$ \\
\hline$\chi$ & $\begin{array}{l}\text { Crystal Silicon } \\
\text { electron affinity }\end{array}$ & $4.05 \mathrm{ev}$ \\
\hline $\mathrm{m}$ & ITO thickness & $0.1 \mu \mathrm{m}$ \\
\hline
\end{tabular}

carrier collection efficiency though this structure which has much more junction area. Indeed the IQE response in the 


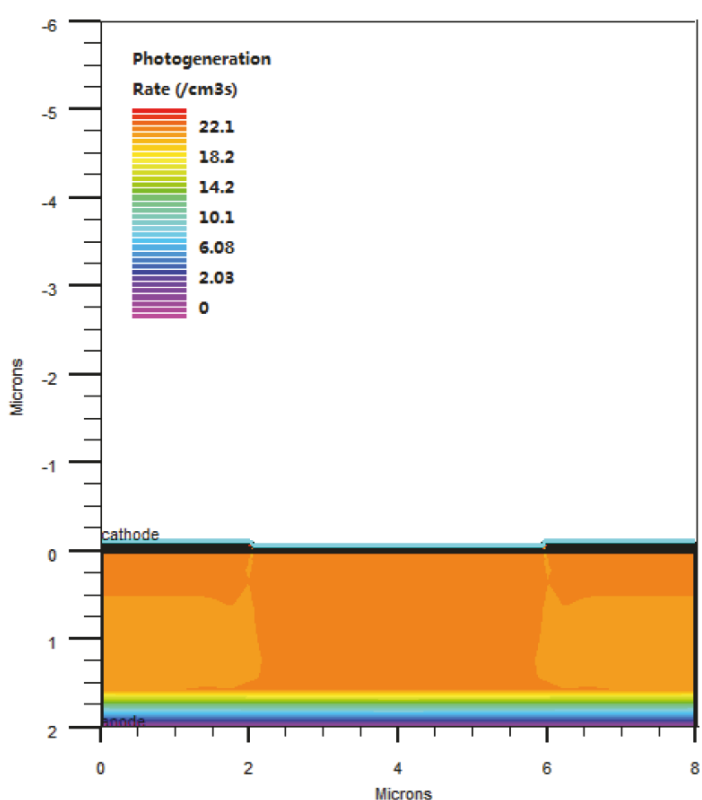

(a)

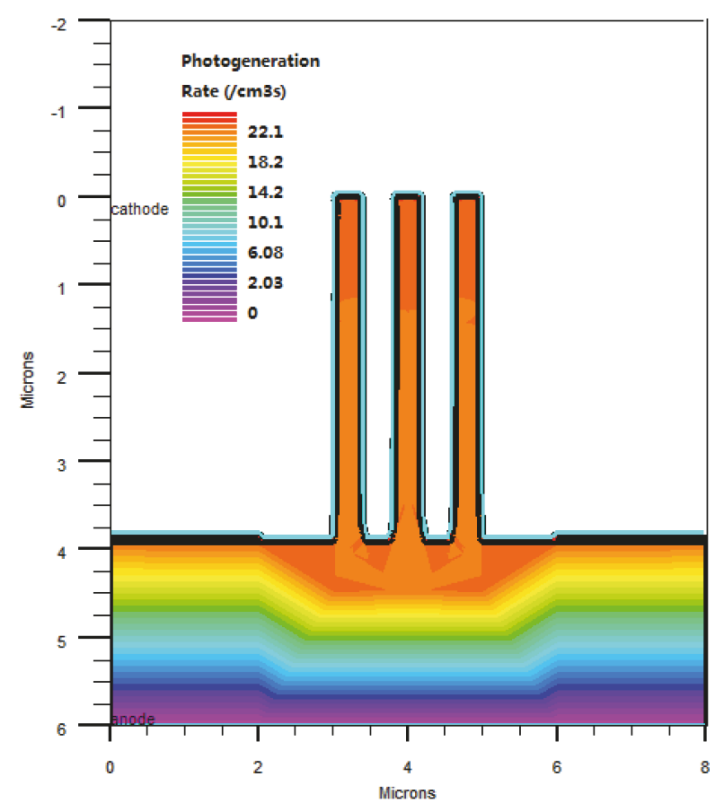

(b)

FIGURE 3: Photogeneration rate of silicon based solar cell (a) planar $p-n$ junction on $2 \mu \mathrm{m}$ thick substrate; (b) radial core-shell junction with $4 \mu \mathrm{m}$ length nanowires on $2 \mu \mathrm{m}$ thick substrate.

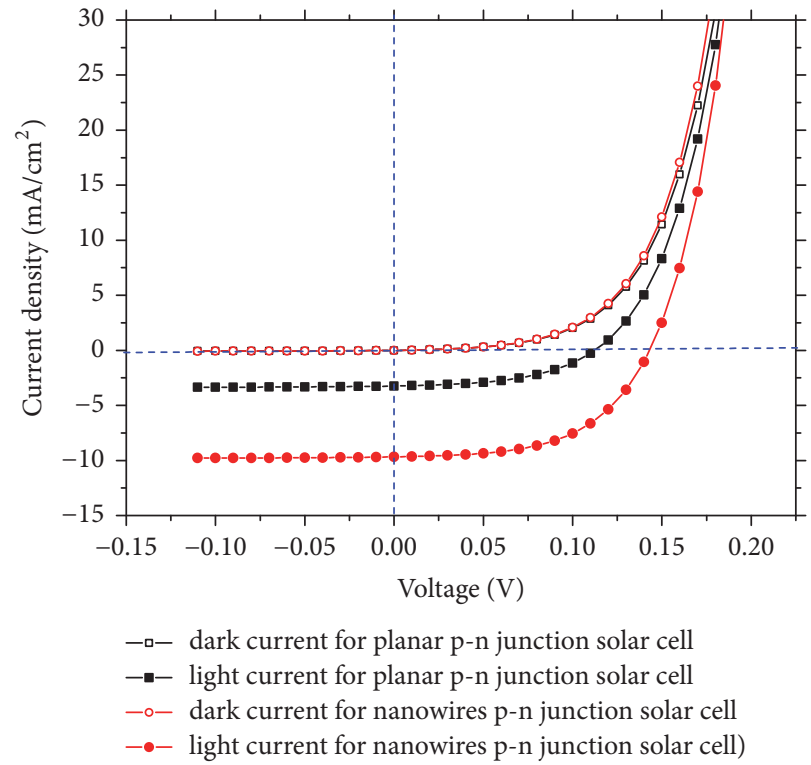

(a)

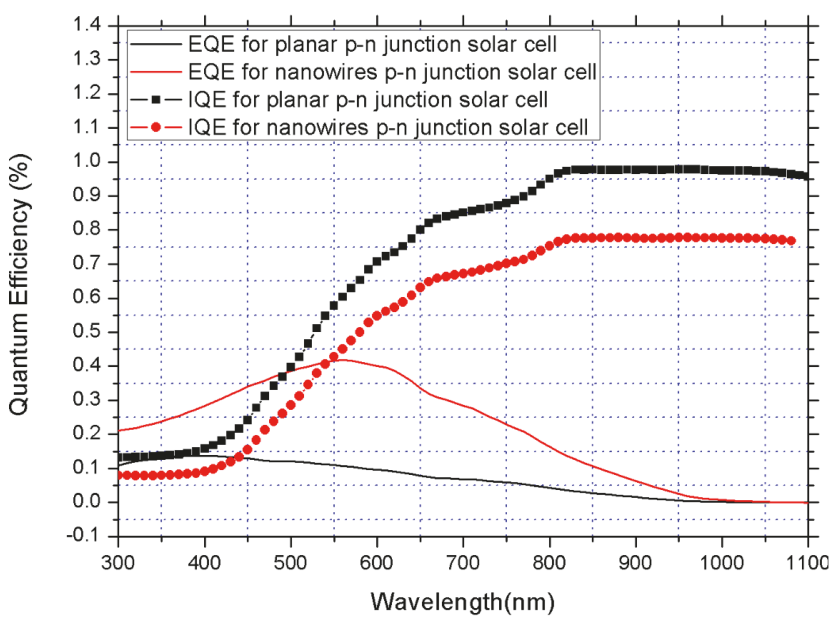

(b)

FIgURE 4: Photovoltaics performance of the planar and nanowires $p$ - $n$ junction solar cell: (a) $J-V$ curves of planar $p$ - $n$ junction on $2 \mu$ m thick substrate; (b) EQE and IQE of $4 \mu \mathrm{m}$ nanowires radial core-shell junction on $2 \mu \mathrm{m}$ thick substrate.

400-800 nm wavelength region increases with the absorption coefficient and then followed a slow saturation.

3.2. Nanowires Diameter Dependence. To achieve enhanced carriers collection efficiency in nanowire device, the effective field must be needed. A radial heterojunction has at least an electron or hole effective field present, since at least on the affinities at nanowire interface, which has strong effect on the charge carrier separation. In order to analyze the carriers' collection mechanism, we have directly compared the minority carrier current density distribution versus nanowire diameter in Figure 5. The accuracy control of the device simulations shows the dependence of electric field on charge carriers' separation.

A close examination of photovoltaics performance for radial junction solar cell versus diameter in Figure 6 gives 


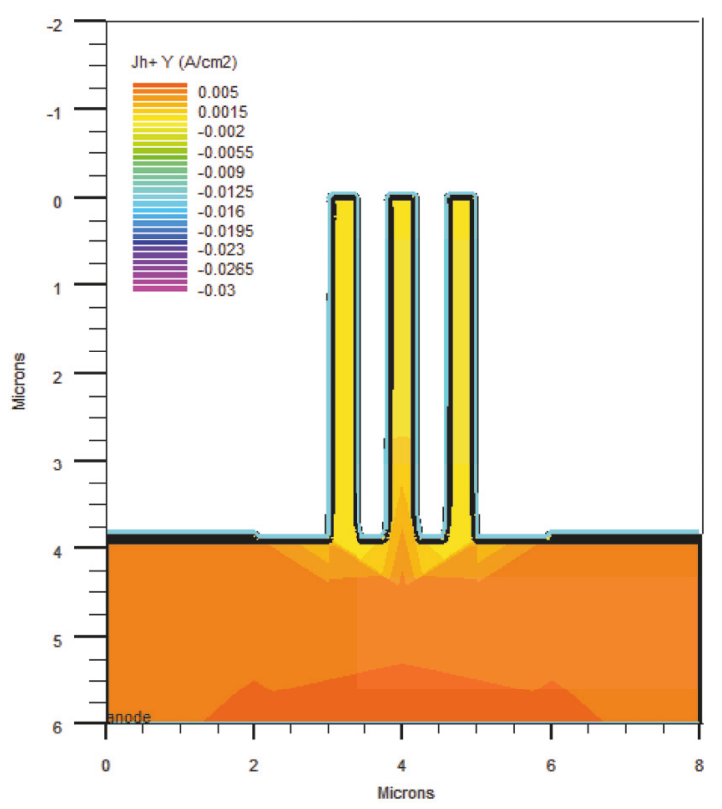

(a)

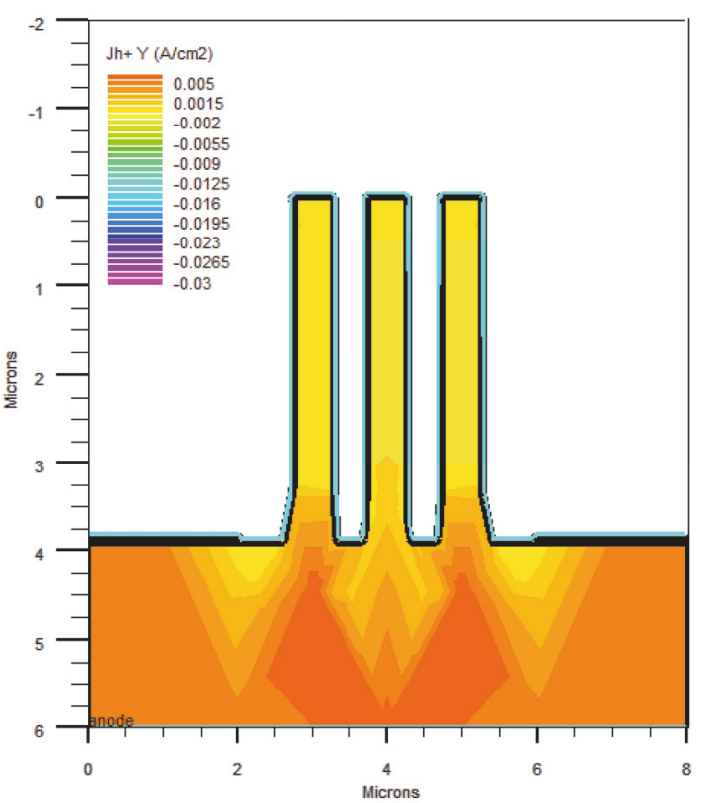

(b)

FIGURE 5: Cross section of holes current density distribution: (a) nanowires diameter set as $300 \mathrm{~nm}$, periodicity set as $600 \mathrm{~nm}$; (b) nanowires diameter set as $500 \mathrm{~nm}$, periodicity set as $1000 \mathrm{~nm}$.

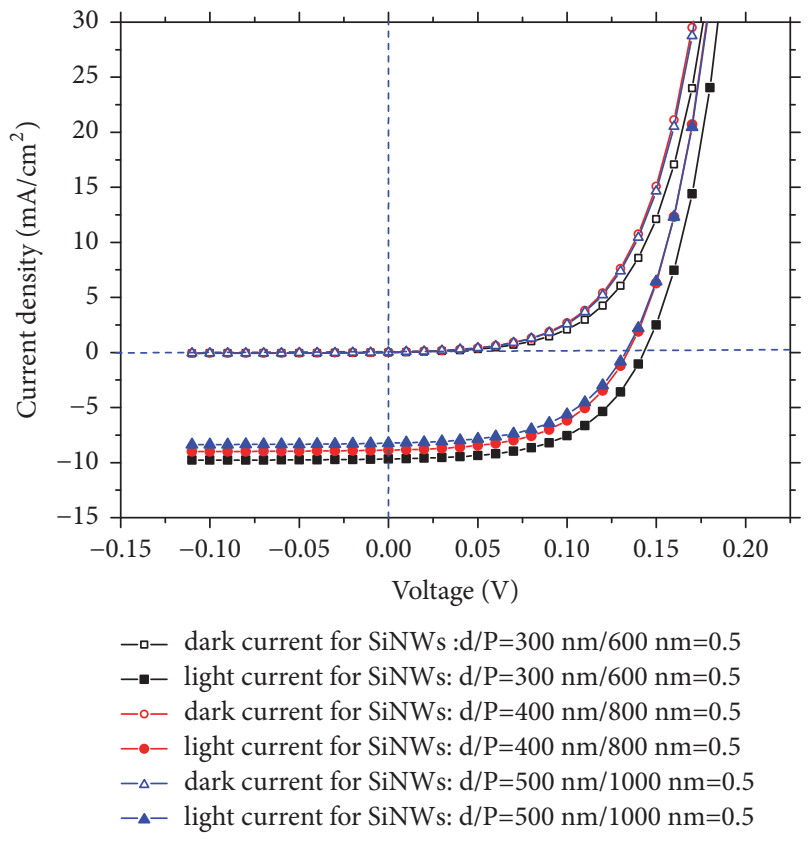

(a)

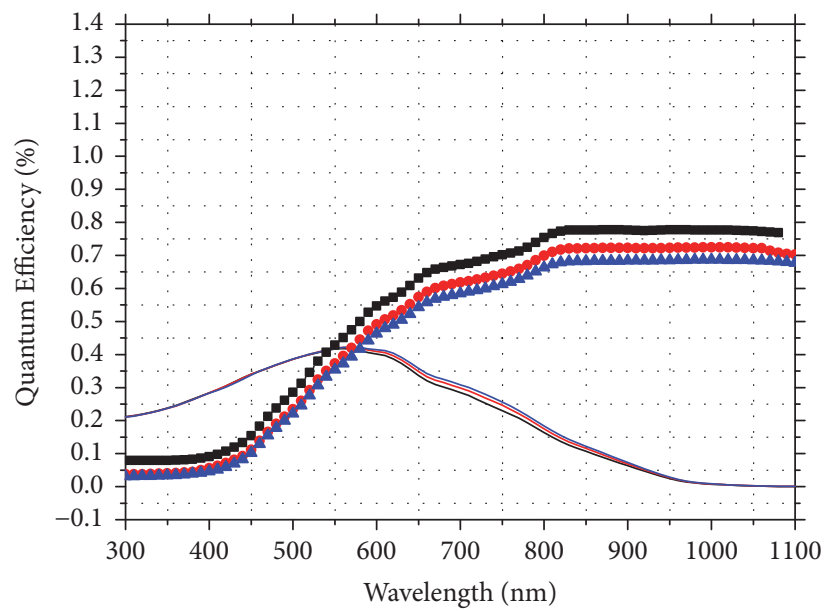

EQE for SiNWs: $\mathrm{d} / \mathrm{P}=300 \mathrm{~nm} / 600 \mathrm{~nm}=0.5$

— EQE for SiNWs: $d / P=400 \mathrm{~nm} / 800 \mathrm{~nm}=0.5$

— EQE for SiNWs: $\mathrm{d} / \mathrm{P}=500 \mathrm{~nm} / 1000 \mathrm{~nm}=0.5$

-- IQE for SiNWs: $\mathrm{d} / \mathrm{P}=300 \mathrm{~nm} / 600 \mathrm{~nm}=0.5$

-•- IQE for SiNWs: $\mathrm{d} / \mathrm{P}=400 \mathrm{~nm} / 800 \mathrm{~nm}=0.5$

-^- IQE for SiNWs: d/P=500 nm/1000 nm=0.5

(b)

FiguRE 6: Photovoltaics performance of nanowires radial $p$ - $n$ junction solar cell versus diameter: (a) $J-V$ curves for $0.3 \mu \mathrm{m}, 0.4 \mu \mathrm{m}$, and 0.5 $\mu \mathrm{m}$; (b) EQE and IQE for $0.3 \mu \mathrm{m}, 0.4 \mu \mathrm{m}$, and $0.5 \mu \mathrm{m}$, receptively.

more evidences of this limitation of carrier collection. With the increasing of nanowire diameter based on a fixed ratio of $0.5, J_{s c}$ decreased from $9.52 \mathrm{~mA} / \mathrm{cm}^{2}$ to $8.026 \mathrm{~mA} / \mathrm{cm}^{2}$, and $V_{o c}$ decreased from $0.145 \mathrm{~V}$ to $0.134 \mathrm{~V}$. However, in contrast to the photovoltaics performance, EQE response showed an increase resulting from increase in light absorption area.
The decrease of $J_{s c}$ and $V_{o c}$ can be evidenced by IQE response presented in Figure 6(b). The bigger nanowire diameter means longer minority carrier diffusing length. Since collection lengths' direction is orthogonal with light absorption direction in radial nanowire solar cell, the horizontal collection of carriers results in shorter distance that 

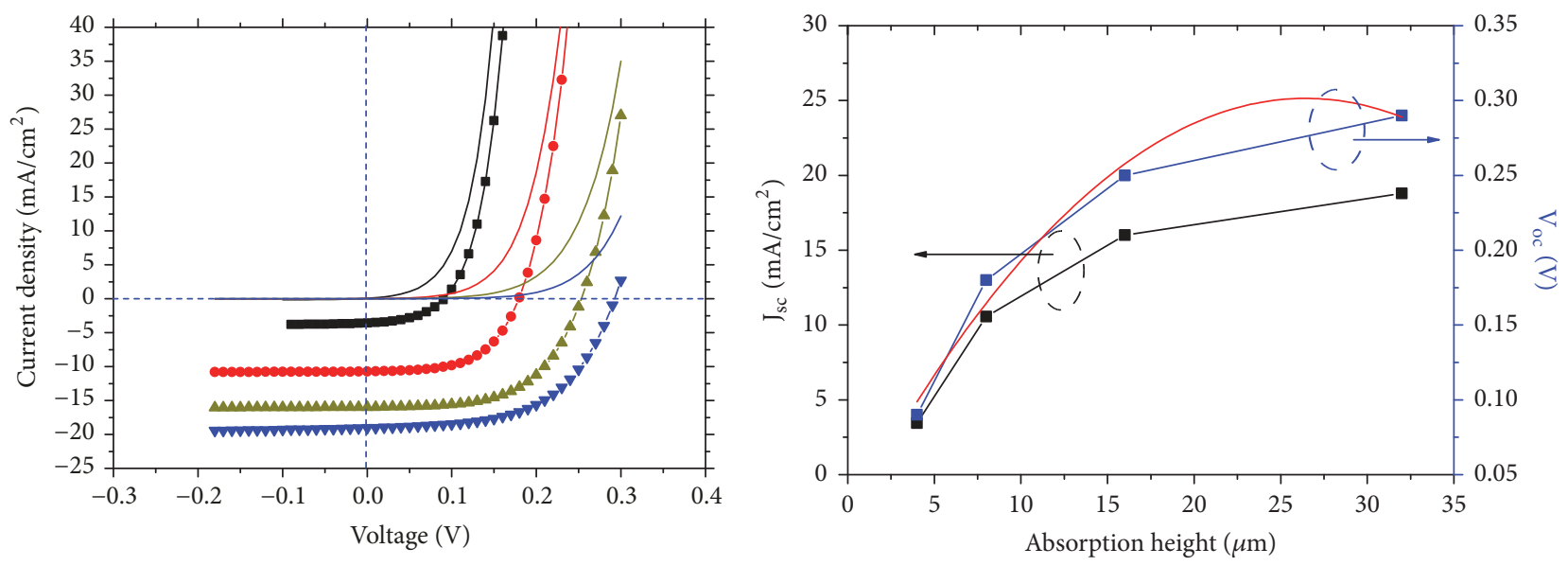

—- dark current with $4 \mu \mathrm{m}$ absorption height
- - light current with $4 \mu \mathrm{m}$ absorption height
- dark current with $8 \mu \mathrm{m}$ absorption height
- - light current with $8 \mu \mathrm{m}$ absorption height
- dark current with $16 \mu \mathrm{m}$ absorption height
- light current with $16 \mu \mathrm{m}$ absorption height
- dark current with $32 \mu \mathrm{m}$ absorption height
- light current with $32 \mu \mathrm{m}$ absorption height

(a)

(b)

FIGURE 7: Photovoltaics performance of nanowires radial $p-n$ junction solar cell: (a) $J-V$ curves for total absorption versus different height; (b) $J_{s c}$ and $V_{o c}$ as a function of the absorber height with the same nanowire length.

TABLE 2: Summary of device performance of nanowires core-shell solar cell.

\begin{tabular}{|c|c|c|c|c|c|c|c|}
\hline $\begin{array}{l}\text { SiNWs } \\
\text { diameter } \\
\text { “d” }(\mu \mathrm{m})\end{array}$ & $\begin{array}{l}\text { SiNWs } \\
\text { length } \\
\text { “h” }(\mu \mathrm{m})\end{array}$ & $\begin{array}{c}\text { Total absorption } \\
\text { height } \\
\text { "h"+ “H” }(\mu \mathrm{m})\end{array}$ & $\begin{array}{c}\text { Filling } \\
\text { Ratio } \\
(\mathrm{d} / \mathrm{P}) \\
\end{array}$ & $\begin{array}{c}J s c \\
\left(\mathrm{~mA} / \mathrm{cm}^{2}\right)\end{array}$ & $\operatorname{Voc}(\mathrm{V})$ & $F F(\%)$ & $\eta(\%)$ \\
\hline 0.3 & 4 & 4 & 0.5 & 3.44 & 0.09 & 47.86 & 0.14 \\
\hline 0.3 & 4 & 8 & 0.5 & 10.56 & 0.18 & 57.11 & 1.08 \\
\hline 0.3 & 4 & 16 & 0.5 & 16.01 & 0.25 & 58.57 & 2.34 \\
\hline 0.3 & 4 & 32 & 0.5 & 18.82 & 0.29 & 57.48 & 3.13 \\
\hline
\end{tabular}

leads to more current; however, it can also lead to more recombination and therefore decrease the open-circuit voltage.

3.3. Absorber Height Dependence. We have carried out a parametric study on the impact of the total absorber height which includes nanowire length and substrate thickness. The total height has been varied from $4 \mu \mathrm{m}$ to $32 \mu \mathrm{m}$. Figure 7(a) shows the $J-V$ characteristics of the redial core-shell cells with four different absorber heights. All devices had the same nanowire length, the same nanowire diameter, and a fixed $d / P$ ratio of 0.5 . The minimum value of $J_{s c}$ for the lowest height of absorber $4 \mu \mathrm{m}$, which means that the photoinduced current comes from silicon nanowires, is $3.44 \mathrm{~mA} / \mathrm{cm}^{2}$. Moreover, further increase of substrate thickness leads to the increase of $J_{s c}$, which has the same variation trend of $V_{o c}$, as listed in Table 2. This can be explained by an increase of photogenerated carrier in total junction area.

The parameters $J_{s c}$ and $V_{o c}$ were plotted as a function of the absorption height. We notice that in Figure $7(b)$ the variation trend of the $J_{s c}$ is also consistent with the trend of $V_{o c}$; both shows a saturation for the further increase of absorption height. On the other hand, FF remains fairly constant while getting a peak value at absorption of $16 \mu \mathrm{m}$. For thin absorber, nanowires array light trapping dominates the performance. On the other hand, the carrier collection dominates the photovoltaics output for thicker cells since the substrate absorbs a large proportion of incident light.

\section{Conclusions}

In summary, we have performed a numerical simulation study on the optical and electrical properties in silicon nanowires radial core-shell junction solar cell. The periodic array structure was structured using direct dry etching method in order to obtain a detailed analysis on the relationship between fabrication and cell output characteristics. Compared to the planar device, radial junction solar cell gave rise to a large increase in current density from $3.36 \mathrm{~mA} / \mathrm{cm}^{2}$ to $9.52 \mathrm{~mA} / \mathrm{cm}^{2}$, resulting from better light 
harvesting performance. On the other hand, lower IQE response of nanowires solar cell suggests that the built-in voltage is not sufficient in carriers' collection. Moreover, the diameter dependence and absorber height dependence were investigated at a fixed shell thickness and doping concentration; the variation in IQE and saturation in $J_{s c}$ indicate that the device performance is limited by the carrier collection in radial junction.

\section{Data Availability}

The data used to support the findings of this study are available from the corresponding author upon request.

\section{Conflicts of Interest}

The authors declare that they have no conflicts of interest.

\section{Acknowledgments}

The project was supported by research fund of Changshu Industry Technological Innovation (no. CQ201602), Jiangsu Province Natural Science Research Programs of Higher Schools (no. 17KJB510001), Suzhou Industry Technological Innovation (no. SYG201602), and National Natural Science Foundation of China (Grants nos. 61674022, 61404012, and 61306122).

\section{References}

[1] M. D. Kelzenberg, S. W. Boettcher, J. A. Petykiewicz et al., "Enhanced absorption and carrier collection in Si wire arrays for photovoltaic applications," Nature Materials, vol. 9, no. 3, pp. 239-244, 2010.

[2] E. C. Garnett and P. Yang, "Silicon nanowire radial p-n junction solar cells," Journal of the American Chemical Society, vol. 130, no. 29, pp. 9224-9225, 2008.

[3] E. Garnett and P. Yang, "Light trapping in silicon nanowire solar cells," Nano Letters, vol. 10, no. 3, pp. 1082-1087, 2010.

[4] W. Deng, L. Huang, X. Xu et al., "Ultrahigh-Responsivity Photodetectors from Perovskite Nanowire Arrays for Sequentially Tunable Spectral Measurement," Nano Letters, vol. 17, no. 4, pp. 2482-2489, 2017.

[5] D. Zheng, J. Wang, W. Hu et al., "When Nanowires Meet Ultrahigh Ferroelectric Field-High-Performance Full-Depleted Nanowire Photodetectors," Nano Letters, vol. 16, no. 4, pp. 25482555, 2016.

[6] D. Zheng, H. Fang, P. Wang et al., "High-Performance Ferroelectric Polymer Side-Gated CdS Nanowire Ultraviolet Photodetectors," Advanced Functional Materials, vol. 26, no. 42, pp. 7690-7696, 2016.

[7] Z. Sun, Z. Shao, X. Wu, T. Jiang, N. Zheng, and J. Jie, "Highsensitivity and self-driven photodetectors based on Ge-CdS core-shell heterojunction nanowires: Via atomic layer deposition," CrystEngComm, vol. 18, no. 21, pp. 3919-3924, 2016.

[8] P. Yu, J. Wu, S. Liu, J. Xiong, C. Jagadish, and Z. M. Wang, "Design and fabrication of silicon nanowires towards efficient solar cells," Nano Today, vol. 11, no. 6, pp. 704-737, 2016.

[9] X. Wang, K. L. Pey, C. H. Yip, E. A. Fitzgerald, and D. A. Antoniadis, "Vertically arrayed Si nanowire/nanorod-based core-shell p-n junction solar cells," Journal of Applied Physics, vol. 108, no. 12, Article ID 124303, 2010.

[10] R. Elbersen, W. Vijselaar, R. M. Tiggelaar, H. Gardeniers, and J. Huskens, "Effects of Pillar Height and Junction Depth on the Performance of Radially Doped Silicon Pillar Arrays for Solar Energy Applications," Advanced Energy Materials, vol. 6, no. 3, Article ID 1501728, 2016.

[11] M. M. Adachi, M. P. Anantram, and K. S. Karim, "Core-shell silicon nanowire solar cells," Scientific Reports, vol. 3, article 1546, 2013.

[12] J. Li, H. Yu, S. Wong et al., "Si nanopillar array optimization on Si thin films for solar energy harvesting," Applied Physics Letters, vol. 95, no. 3, Article ID 033102, 2009.

[13] S. M. Wong, H. Y. Yu, J. S. Li et al., "Si nanopillar array surfacetextured thin-film solar cell with radial p-n junction," IEEE Electron Device Letters, vol. 32, no. 2, pp. 176-178, 2011.

[14] Y. Li, P. Gao, Q. Chen, J. Yang, J. Li, and D. He, "Nanostructured semiconductor solar absorbers with near $100 \%$ absorption and related light management picture," Journal of Physics D: Applied Physics, vol. 49, no. 21, Article ID 215104, 2016.

[15] J. Li, H. Yu, S. M. Wong et al., "Design guidelines of periodic Si nanowire arrays for solar cell application," Applied Physics Letters, vol. 95, no. 24, Article ID 243113, 2009.

[16] W. Q. Xie, W. F. Liu, J. I. Oh, and W. Z. Shen, “Optical absorption in c-Si/a-Si:H core/shell nanowire arrays for photovoltaic applications," Applied Physics Letters, vol. 99, no. 3, Article ID 033107, 2011.

[17] B. M. Kayes, H. A. Atwater, and N. S. Lewis, "Comparison of the device physics principles of planar and radial $\mathrm{p}$-n junction nanorod solar cells," Journal of Applied Physics, vol. 97, no. 11, Article ID 114302, 2005.

[18] Software and Device Simulation Silvaco Inc., "ATLAS User's Manual," no. 408, pp. 567-1000, 2010.

[19] Y. Kuang, Y. Liu, Y. Ma, X. Hong, X. Yang, and J. Feng, "Theoretical study on graphene silicon heterojunction solar cell," Journal of Nanoelectronics and Optoelectronics, vol. 10, no. 5, pp. 611-615, 2015.

[20] K. Ding, X. Zhang, F. Xia et al., "Surface charge transfer doping induced inversion layer for high-performance graphene/silicon heterojunction solar cells," Journal of Materials Chemistry A, vol. 5, no. 1, pp. 285-291, 2017. 

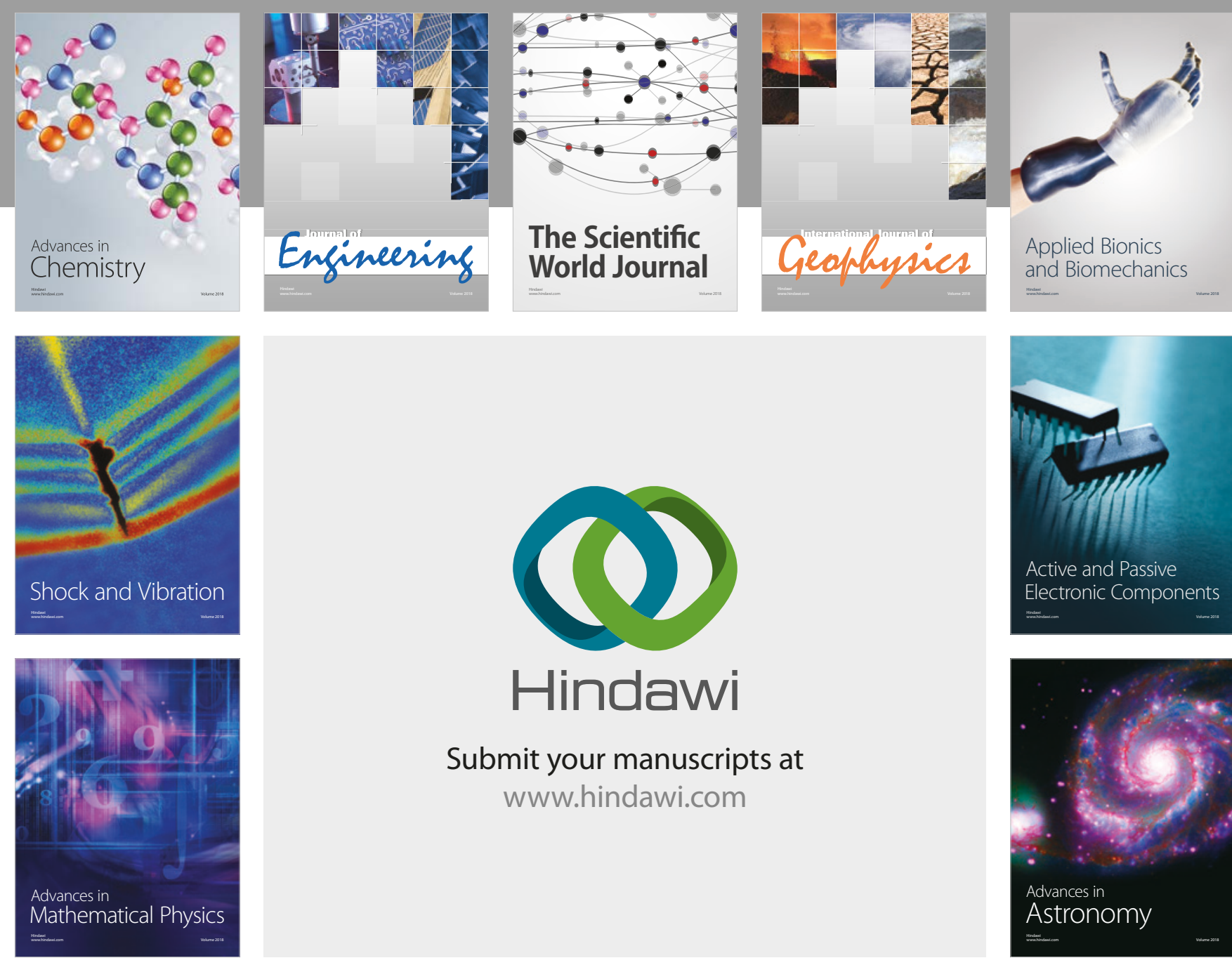

Submit your manuscripts at

www.hindawi.com

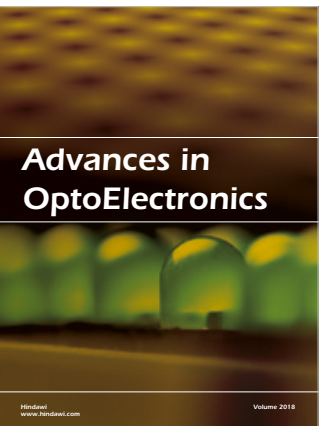

\section{Rotcting Machinery}
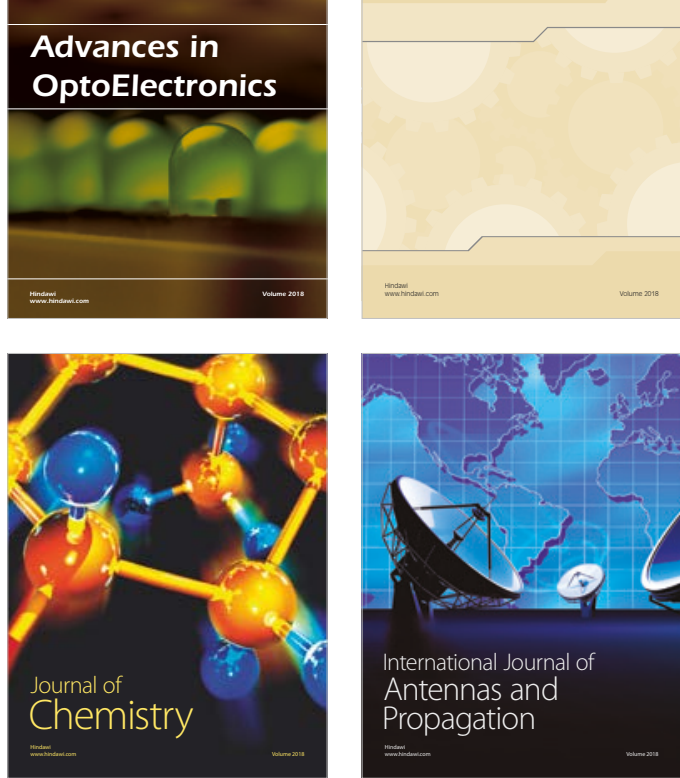

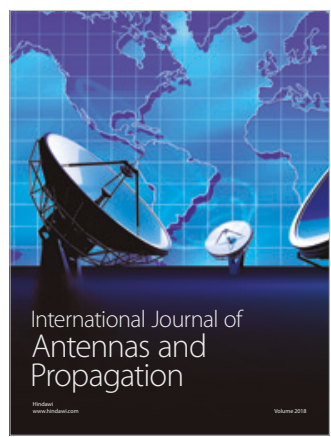

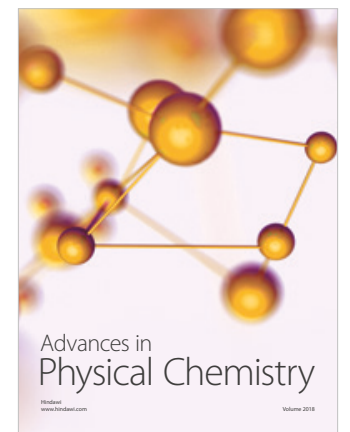

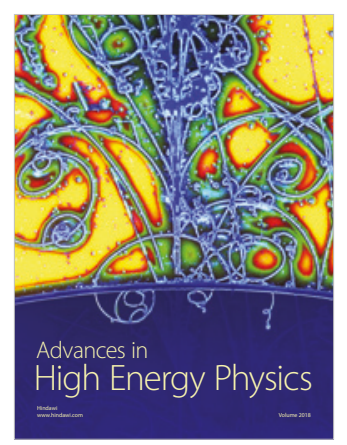

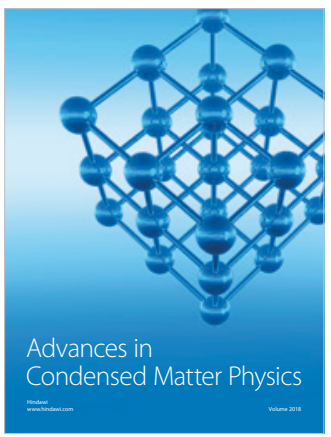

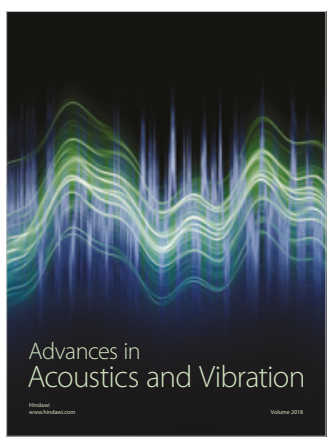

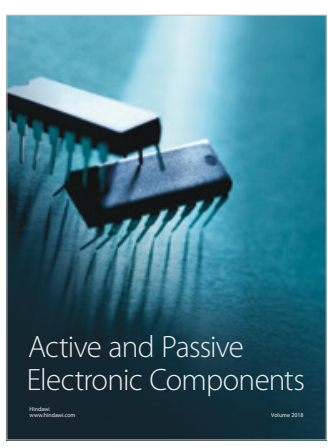
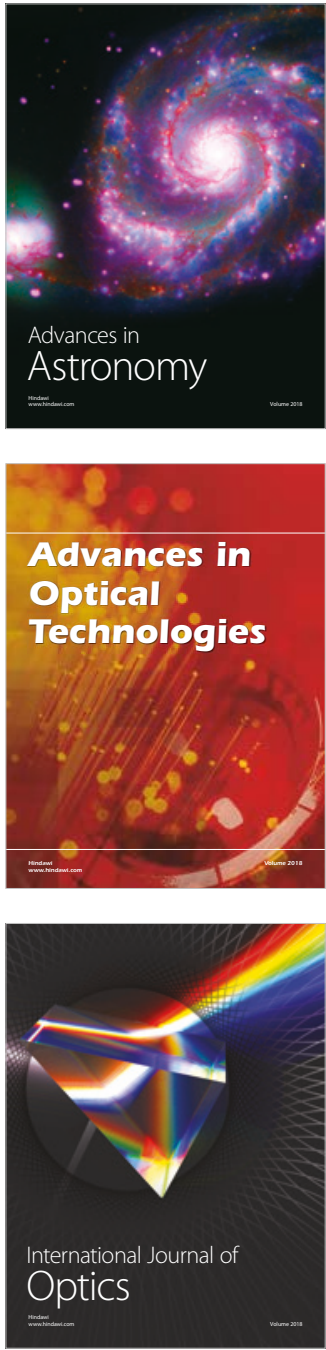